- As propostas de fornecimento a Ministérios, feitas por sociedades comerciais, estão sujeitas ao pagamento de sélo proporcional.

\title{
MINISTÉRIO DA FAZENDA
}

\section{DESPACHO}

1. O Ministério da Aeronáutica, por sua Consultoria Jurídica, pergunta se es propostas de venda de gasolina que lhe sãe feitas pela Standard Oil Co. of Brasil sofrem ou não $a$ incidência do sêlo proporcional.

2. As propostas de fornecimento de gasolina aceitas e executadas, entre a Cia e o Ministério, envolvendo condições, direitos e obrigações de parte a parte, têm, inegàvelmente, a feição de contrato bilateral de compra venda.

3. O art. $38 \mathrm{da}$ Tabela anexa ao D. L. n. 4.655 , de 3-9-42, submete a sêlo proporcional

"contrato de compra e venda de bens móveis e imóveis".

Nota:

1.8

2. ${ }^{\text {a }}$ Estão isentos:

Os pedidos de mercadorias e suas confirmações, ou aceitação, celebrados entre comerciantes, industriais ou agricultores, para fins mercantis, exceto quando ajuizados ou registrados no Registro de Títulos e Documentos.

4. As propostas de fornecimentos em questão entre o Ministério e uma sociedade comercial não se ajustam à isenção transcrita visto que não são celebrados entre "comerciantes, industriais ou agricultores, para fins mercantes, estando, consequientemente, obrigados ao sêlo proporcional correspondente. 
5. Poder-se-ia alegar que as aceitações das propostas competem ao Ministério e nesse caso, também, o ônus do impôsto.

6. Mas, ante o estipulado no $\$ 3 .^{\circ}$ do art. $20^{\circ}$ das N. G. do D. L. n. 4.655, de 3-9-42, "havendo mais de um signatário, se algum dêles gozar de isenção, o ônus do impôsto recairá sôbre os demais".

7. Como elementos de elucidação à questão transmita-se por cópia a decisão desta R D. F na consulta da E. F. C. B. - publicada no Diário Oficial de 21-7-44 - que aborda a matéria com prismas mais amplos.

$$
* * *
$$

"Processo n. 90.703-44 - Estrada de Ferro Central do Brasil consulta sôbre o impôsto do sêlo.

\section{Despacho:}

1. A E.F.C.B. apresenta uma relação de contas que pagou a diversas firmas comerciais, por fornecimentos de materiais, sem que fôssem seladas proporcionalmente.

2. Pede, entretanto, novo exame da matéria por discordar da resposta que anteriormente lhe foi transmitida, no sentido de que os pedidos, coletas e propostas de fornecimentos de materiais aceitos e executados sem contratos escritos, são considerados contratos imperfeitos de compra e venda, sujeitos ao sêlo proporcional.

3. Em conseqüência da solução dada à E. F. C. B. surgiu representação da D. M. do M.F. onde esta R.D.F., confirmando sua decisão, demonstrou cabalmente as razóes legais do seu pronunciamento que exige sêlo proporcional nos papéis em questão.

4. Enquanto perdurarem as disposiçōes do Decreto-lei n. 4.655 , do 3-9-42, esta R. D. F. não pode ter, sôbre o assunto, outro critério, senão o que já manifestou à própria E. F. C. B.

5. Transmita-se cópia da decisão citada, constante do processo número

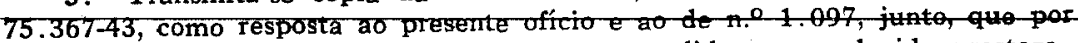
circunstâncias especiais, não pôde ser, antes, atendido com a devida presteza.

6. Em seguida proceda-se à intimação das firmas relacionadas para o pagamento do impôsto devido, de acôrdo com o art. 46 das normas gerais do D. L. n. 4.655 , citado.

R. D. F., em 12 de julho de 1944. - Pascoal Ranieri Mazzilli, Diretor.

A decisão a que se referess os itens 3 e 5 é a seguinte:

"Esta R. D. F., atendendo a uma solicitação da E. F, C. B. a respeito da incidência dọ impôsto do sêlo nas propostas de fornecimento de materiais, teve ocasião de assim manifestar-se:

"A E.F.C.B. solicita novos esclarecimentos a respeito da consulta cuja resposta juntamos cópia.

2. Versa a mesma sôbre a incidência do impôsto do sêlo nas propostas de fornecimentos que lhes são apresentados.

3 - Foi-lhe respondido. 
I - "Os papéis que forem apresentados à Estrada, em concorrência, para fornecimento de materiais, coletas de preço, etc., incidem no impôsto do sêlo expresso no art. 84 da tibela anexa ao D. L. n. 4.655 , de $3-9-42$, isto é, Cr\$1,00 por fôlha: e

II - Uma vez aceitos para a sua execução ficam sujeitos a sêlo proporcional, na forma dos arts. 40 e 46 das normas gerais do referido regulamento".

4. A Estrada indaga, agora, se o sêlo proporcional citado no item II da resposta incide apenas sôbre os contratos referidos no art, 46 do Decreto número 4.655 , de $3-9-42$, ou se também sôbre as propostas aceitas e executadas, sem contrato.

5. Segundo as disposições contidas no Código de Contabilidade Pública da União - Decreto n..$^{15.789}$, de 8-11-1922 - os fornecimentos ao Estado são feitos mediante concorrência pública ou administrativa e precedem os contratos (arts: 736 e seguintes).

6. Esses contratos por sua vez podem ser: art. 232: perfeitos, quando nêles se contém todos os elementos necessários a sua execução integral, tanto ao objeto como ao prazo, quantidade, preço, etc.

Imperfeitos são os que, de início, uma ou algumas daquelas condições não possam ser fixadas.

7. Na primeira hipótese o sêlo proporcional será aplicado de acôrdo com o art. 40 do decreto citado e na segunda será cobrado na forma do art. 46 .

8. A proposta aceita e executada sem contrato enquadra-se, na espécie, às condições de contrato imperfeito e dêsse modo o sêlo proporcional será cobrado nas contas respectivas, como recomenda o precitado art. 46 .

9. Ainda sôbre o assunto, há os elementos elucidativos constantes da decisão proferida pela $D$. R. I. em ofício n. 874 , ao D. A. do M. A. proferida no Diário Oficial de 1-10-42.

A decisão da D. R. I., embora dada na vigência da anterior lei do sêlo, não perdeu, para o caso, a sua utilidade pela orientação que encerra. Ei-la:

I - "As contas apresentadas às repartições públicas, quando não sujeitas ao sêlo proporcional, estãs sujeitas apenas, do sêlo previsto no art. 34 da tabela anexa ao D. L. n. 4.274 , de 17-4-42, livre portanto, do sêlo indicado no art. 100 da referida tabela;

II - Continua de pé a decisão do Tesouro constante do ofício n. 51 , do Diretor Geral da Fazenda Nacional do Ministério da Guerra, publicado no Diário Oficial de 4-9-36.

III - O sêlo proporcional pago nas contas apresentadas às repartições, corresponde ao sêlo que deixou de ser pago nos respectivos contratos;

IV - Se as contas referidas pagaram sêlo proporcional, o recibo nelas passado está isento do sêlo;

V Nas contas aludiủas, qüer sujeitás ao sêlo fixo, quer ao proporcional, o sêlo sòmente é devido nas primeiras vias, e, no caso, não cabe a formalidade da averbação prevista no art $40,82 .^{\circ}$, das normas gerais".

A.D. F. do M. F. diz categòricamente que as contas que lhe são apresentadas não estão sujeitas ao sêlo proporcional e que é imperfeita a citação dos artigos do Código de Contabilidade, à vista do Decreto n. 2.206 , de 20-5-40. 
De início é preciso ressaltar que a consulta em debate é no sentido de propostas de material aceitas e executadas que encerram obrigaçóes de parte a parte, e têm inegàvelmente a fôrça e as condições de um contrato, bilateral, de compra e venda.

Um simples pedido de material que, fornecido, sem outras formalidades, redunda na conta apresentada, é outra coisa .....

$O$ ponto de vista desta $R$. D. F. de que as contas apresentadas às Repartições, oriundas de propestas, coletas de preço etc, devidamente confirmadas ou aceitas, estão obrigadas ao sêlo proporcional, repousa na verdadeira inteligência da nota $2 .^{a}$ do art. 38 da Tabela da atual lei do sêlo:

Art. 38 - Contratos de compra e venda.

Notas

$10^{\mathrm{a}}$

2.a Estão isentos:

Os pedidos de mercadorias e suas confirmações, ou aceitação, celebrados entre comerciantes, industriais ou agricultores, para fins mercantis.

O art. 191 do Código Comercial considera ùnicamente mercantil a compra e venda de efeitos móveis quando há revenda, por grosso ou a retalho.

Ora, a proposta do fornecimento de material aceita e executada, verdadeiro contrato de compra e venda entre uma repartição e uma firma comercial, não é celebrada entre comerciantes, industriais ou agricultores, nem tem fins mercantis, porque não há revenda.

Estão pois excluídos da isenção e sujeitos ao sêlo proporcional correspondente.

O Banco do Brasil, instituição modelar que honra o pás e prima pela fiel execução das leis, vem, segundo consta do processo n. $77.667-42$, desta R. D. F, selando proporcionalmente os pedidos de mercadorias para o seu uso, pois, não se destinando à revenda, não têm fins mercantis e não gozam assim da isenção acima citada.

Por á se vê que nem todos os departamentos diretos ou indiretos da administração pública se aproveitam da falsa interpretação de que qualquer conta apresentada à Repartição proveniente dos pedidos de mercadorias sem contratos, apenas estão sujeitas ao sêlo fixo de $\mathrm{Cr} \$ 2,00$, consignado no art. 34 da Tabela.

Procurando esclarecer o assunto, de forma que a consulente melhor se apercebesse da incidência do impôsto do sêlo nos papéis atinentes aos fornecimentos de materiais ao Estado, foram citados os artigos do Código de Contabilidade.

O Decreto n.o 2.206, de 20-5-40, dispondo sôbre serviços de material e reforma da C. C. C., não os revogou expressamente; antes os revigorou, ampliando as suas disposiçóes.

$\mathrm{E}$ tanto isso é verdade que a anterior lei do sêlo, Decreto-lei n. 2.274 , de 17-4-42, considerada por cultores do Direito Fiscal como um dos mais completos regulamentos tributários fiscais, dispunha, em seu art. 46 - normas gerais:

Nos contratos a que se refere o art. 232, parágrafo, alínea $b$, do Regulamento Geral da Contabilidade Pública (Decreto n. ${ }^{\circ} 15.783$, de 8 de novembro de 1922) o sêlo incidirá nas quantias que forem parceladamente pagas pela União.

Sabido, como é, ser regra comezinha de hermenêutica que as leis são interpretadas em conjunto, isolar o art. 232 do n..$^{\circ} 736$, pois ambos se completam e é "diretriz seguida pelos doutos, na interpretação das leis, que "os textos da 
mesma lei deve se entender uns pelos outros, porquanto pelos antecedentes subseqüentes patenteia-se o seu espírito":

Ademais, as concorrências e contratos de que cogitam êsses artigos do Código, foram mantidos nos arts. 35 a 40 do mencionado Decreto n. ${ }^{\circ} 2.206$.

Por um lapso perđoável não foi mencionado, na resposta à Estrada, como revigorando aquelas disposiçōes do Código mas tal imperfeição não invalida o mérito da questão, que é de fato sôbre a incidência do sêlo proporcional nas contas presentes às Repartiçōes, decorrentes de propostas aceitas e cumpridas.

Por essas razões, não vemos motivos para que seja modificada a decisão pro. ferida, a qual, antes deve ser mantida e observada, pois se baseia na legítima exegese da lei do sêlo.

E se, porventura, altera o modus faciendi atual, onerando as transações, como é alegado na representação da D.M., não é, a esta R.D.F. que compete alteração dos textos legais em vigor. S. P. A., em 20 de outubro de 1943. R. Saldanha da Gama, Chefe.

Despacho: Certíssimo. A afirmativa da D.M. quanto a não incidirem no impôsto do sêlo proporcional as contas que lhe são apresentadas por compra de materiais, nas condiçōes da consulta não é de aceitar-se.

A possível controvérsia quanto à vigência dos arts. 736 e seguintes do R. G. C. P., ficou a nosso ver afastada pelo esclarecimento prestado na informaãão, com que estamos de acôrdo. Restitua-se à D. R. I.

Recebedoria do Distrito Federal, 21 de dezembro de 1944. - Paschoal Ranieri Mazzilli, Diretor. 